Article

\title{
Development of Anti-Idiotypic Nanobody-Phage Based Immuno-Loop-Mediated Isothermal Amplification Assay for Aflatoxins in Peanuts
}

\author{
Jiawen Lei ${ }^{1} \mathbb{D}$, Xiaole Han ${ }^{2}$, Xiaoqian Tang ${ }^{3}$, Haiying Wang ${ }^{1}$ and Qi Zhang ${ }^{3, *}$ \\ 1 College of Life Sciences, South-Central University for Nationalities, Wuhan 430074, China; \\ jiawenlei@scuec.edu.cn (J.L.); wanghaiying@mail.scuec.edu.cn (H.W.) \\ 2 College of Chemistry and Material Sciences, South-Central University for Nationalities, Wuhan 430074, \\ China; han-xiaole@mail.scuec.edu.cn \\ 3 Oil Crops Research Institute of the Chinese Academy of Agricultural Sciences, Wuhan 430062, China; \\ tangxiaoqian@caas.cn \\ * Correspondence: zhangqi01@caas.cn; Tel.: +86-27-8681-2943
}

Received: 17 August 2020; Accepted: 1 September 2020; Published: 2 September 2020

\begin{abstract}
Aflatoxin contamination in agricultural products has posed serious health hazards and brought huge economic loss in the food and feed industries. Monitoring aflatoxins in various foods and feeds has become a crucial means to protect public health. This study aimed to report an immuno-loop-mediated isothermal amplification (iLAMP) assay by using an anti-idiotypic nanobody-phage for on-site and rapid detection of aflatoxin in real samples. The iLAMP method was developed on the basis of a competitive immunoassay and LAMP reaction performed in a simple water bath. This method can provide visualized test results: violet color represents positive samples while sky blue represents negative. The visual detection limits of iLAMP for aflatoxin $B_{1}$, $B_{2}, G_{1}$, and $G_{2}$ in peanut samples were $1.6,1.6,3.2$, and $16 \mu \mathrm{g} / \mathrm{kg}$, respectively. The developed assay was verified with high performance liquid chromatography (HPLC) for the analysis of aflatoxins in peanuts, which demonstrated that the iLAMP method can be applied to the detection of aflatoxin in real samples. The novel iLAMP assay eliminates the need for aflatoxin conjugates, the antibody labeling process, and special equipment, and offers an alternative to existing methods with advantages of time-saving, cost-effectiveness, and ease-of-use.
\end{abstract}

Keywords: aflatoxin; LAMP; nanobody; immunoassay

Key Contribution: By using an anti-idiotypic nanobody-phage, an immuno-loop-mediated isothermal amplification (iLAMP) assay was developed for rapid and on-site detection of aflatoxin in real samples.

\section{Introduction}

Aflatoxins are highly toxic secondary metabolites produced by fungal species of Aspergilli, especially Aspergillus flavus and Aspergillus parasiticus [1]. They are listed as group I liver carcinogens by the International Agency for Research on Cancer (IARC) [2]. Till now, more than 20 aflatoxins have been identified, but only Aflatoxins $B_{1}, B_{2}, G_{1}$, and $G_{2}$ occur naturally in a variety of agricultural foodstuffs, especially peanuts and cereals $[3,4]$. Aflatoxin contamination poses a serious threat to human health as well as to the food industry, and has received considerable public attention over the past decades [5]. Monitoring aflatoxins in various food and feeds has become a crucial means to protect public health. Currently, many methods have been developed for aflatoxin detection to meet public concerns about food safety and increasingly stringent analytical requirements, ranging from confirmatory tests in official laboratories to rapid on-site tests in the field [6]. 
As a sensitive, specific and efficient detection method, immunoassay has been widely used in aflatoxin detection, such as enzyme-linked immunosorbent assay (ELISA) [7], immunochromatographic assay (ICA) [8], and immunosensor assay [9]. Nevertheless, all these methods require labelling of antibodies with signal substances (e.g., horseradish peroxidase (HRP), gold nanoparticles (GNPs), and quantum dots (QDs)) to obtain detection signals; the labeling process is often time-consuming and involves tedious covalent coupling chemistry which may result in the loss of antibody activity [10]. Moreover, since aflatoxins are small molecules, they must be coupled to carrier proteins to form aflatoxin conjugates (e.g., $\mathrm{AFB}_{1}-\mathrm{BSA}$ and $\mathrm{AFB}_{1}$-OVA) before use in a competitive immunoassay [11]. Researchers either buy the commercial aflatoxin conjugates or synthesize themselves. Both methods are costly, especially the latter, where the synthesis process is complex and unfriendly to operators and the environment [12]. Previously, we have described an immuno-polymerase chain reaction (iPCR) method for aflatoxin detection in grains and feedstuffs [13]. The iPCR assay was based on an anti-idiotypic nanobody-phage which can mimic the antigen instead of aflatoxin conjugates and contains specific DNA sequence that can be easily amplified. As a consequence, there is no need for the aflatoxin conjugates and antibody labeling process in iPCR assay. Although we have applied the iPCR method to the determination of aflatoxins in real samples, the method has some limitations. First, a complete PCR procedure usually lasts $2-3 \mathrm{~h}$, which is time-consuming and not suitable for rapid testing. Second, PCR requires expensive equipment which may not be available in low-tech environments or in the field. Third, the detection results of iPCR cannot be attained directly and must be calculated by a standard curve, which is not applicable for on-site screening. Therefore, a simple, fast, and cost-effective detection method is still needed to compensate for the limitations of the iPCR assay.

Loop-mediated isothermal amplification (LAMP) is an innovative technique for rapid and easy detection of target nucleic acid [14]. Since first reported in 2000, LAMP has been applied in various fields, such as pathogen detection [15], disease diagnosis [16] and genetically modified (GMO) food identification [17]. As an alternative to PCR-based analysis, LAMP has many significant advantages. Firstly, LAMP has higher specificity and efficiency than PCR by using four specially designed primers for six different regions of the target gene, which enables the amplification to be completed within $1 \mathrm{~h}$ [18-20]. Secondly, LAMP can amplify DNA in isothermal conditions without any thermal cycler by using the Bst polymerase enzyme. Thus, the amplification can be performed in a simple heater, for example, a water bath, which makes on-site testing feasible [21,22]. Finally, the results of LAMP can be easily identified by the naked eye without any special instruments by adding the indicator (e.g., SYBR (Synergy Brands, Inc.) Green I) [23,24]. These unique characteristics of LAMP make it an excellent tool to develop rapid, on-site and point-of-care detection methods for aflatoxins. However, there are no reports on the detection of aflatoxins using LAMP.

In this study, we developed an immuno-LAMP (iLAMP) assay for aflatoxin detection based on anti-aflatoxin monoclonal antibody $1 \mathrm{C} 11$ (mAb 1C11) and anti-idiotypic nanobody-phage $\mathrm{V} 2-5$ specific for $\mathrm{mAb} 1 \mathrm{C} 11$. The novel iLAMP assay eliminates the need for aflatoxin conjugates, antibody labeling process, and special equipment, which offers an alternative to existing methods with advantages of time-saving, cost-effectiveness, and ease-of-use.

\section{Results}

\subsection{Principle of iLAMP}

The principle of iLAMP is shown in Figure 1. The iLAMP method was developed on the basis of a competitive immunoassay and LAMP reaction. Anti-aflatoxin mAb 1C11 [25] was first coated on the bottom of a PCR tube which had been treated with glutaraldehyde. Then, the sample extract and anti-idiotypic nanobody-phage V2-5 were added to the tube simultaneously. Since the nanobody-phage could mimic the antigen (aflatoxin) in the immunoreaction, there was a competition between the phage and aflatoxin in binding with $\mathrm{mAb} 1 \mathrm{C} 11$. After the reaction, the unbound phages were moved out of the tube via the washing step. Subsequently, the LAMP solutions were added to the tube for 
amplification. The color of the mixture in the tube remained violet (positive result) if the sample contained aflatoxin, otherwise, it turned sky blue (negative result).

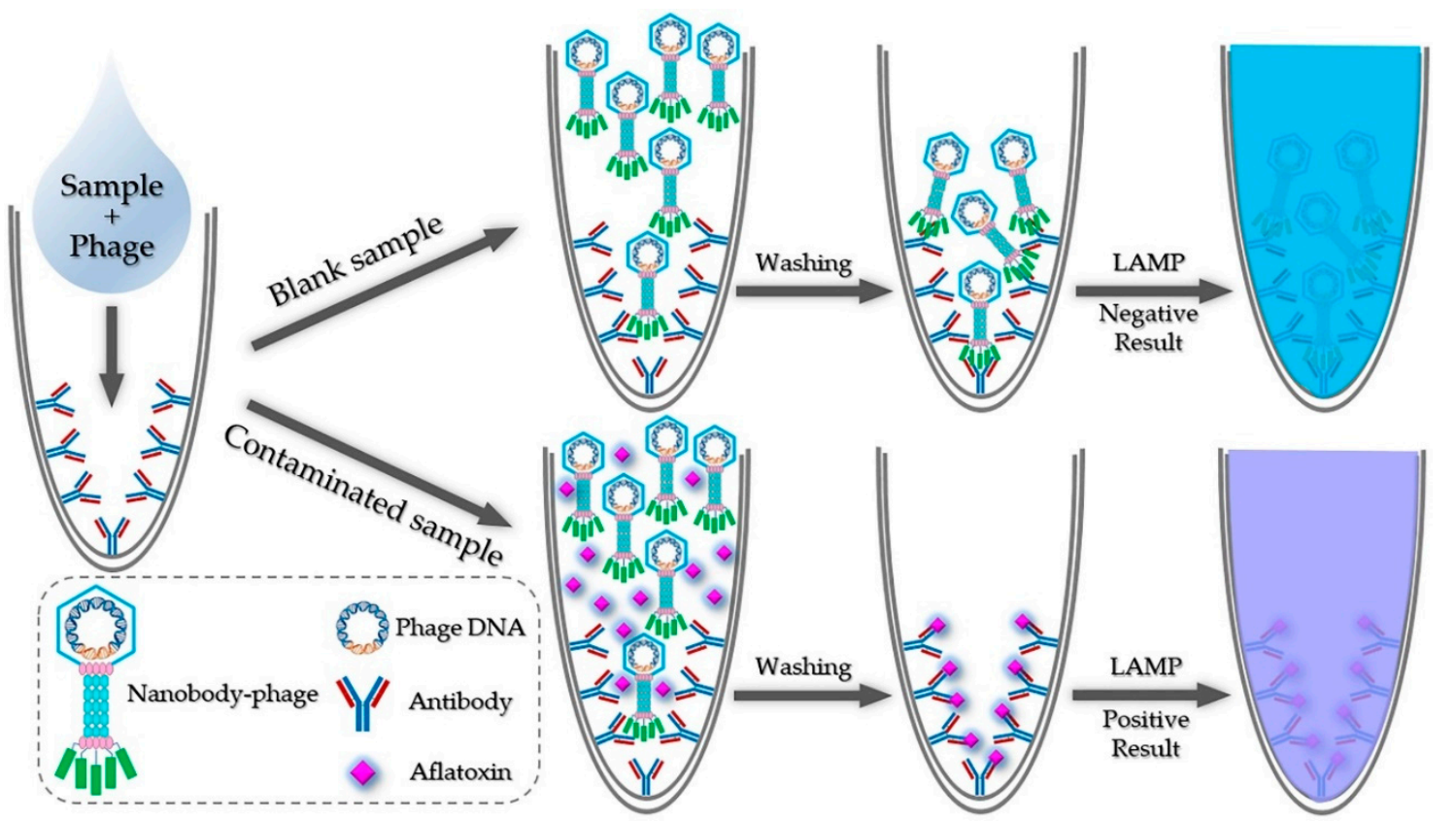

Figure 1. Schematic diagram of the immuno-loop-mediated isothermal amplification (iLAMP). Anti-aflatoxin mAb 1C11 was first coated on the bottom of a polymerase chain reaction (PCR) tube which had been treated with glutaraldehyde. Then, the sample extract and anti-idiotypic nanobody-phage V2-5 were added to the tube simultaneously. Since the nanobody-phage could mimic the antigen (aflatoxin) in the immunoreaction, there was a competition between the phage and aflatoxin in binding with $\mathrm{mAb} 1 \mathrm{C} 11$. After the reaction, the unbound phages were moved out of the tube via the washing step. Subsequently, the LAMP solutions were added to the tube for amplification. The color of the mixture in the tube remained violet (positive result) if the sample contained aflatoxin, otherwise it turned sky blue (negative result).

\subsection{LAMP Primers}

Four primers should be designed for six different regions of the target gene: a forward inner primer (FIP) consisting of F1c and F2, a backward inner primer (BIP) consisting of B1c and B2, a forward outer primer (F3) and a backward outer primer (B3). In this research, five sets of LAMP primers based on the DNA sequence of nanobody phage V2-5 were designed by using Primer Explorer V4 online. The five sets of primers were amplified by LAMP with phage V2-5 as template, and $\mathrm{ddH}_{2} \mathrm{O}$ instead of template was added to the reaction system as negative control. The amplification products were analyzed by $2 \%$ agarose gel electrophoresis (Figure 2). The results showed that the fourth set of primers had the typical trapezoidal bands amplified by LAMP, while other sets of primers did not, indicating that the fourth set of primers had the specific amplification with the DNA of phage V2-5. Therefore, the fourth set of primers was selected as the specific primers in the follow-up experiment. The priming sites and sequence of LAMP targets are shown in Figure 3A, and information on the primers is shown in Figure 3B. 


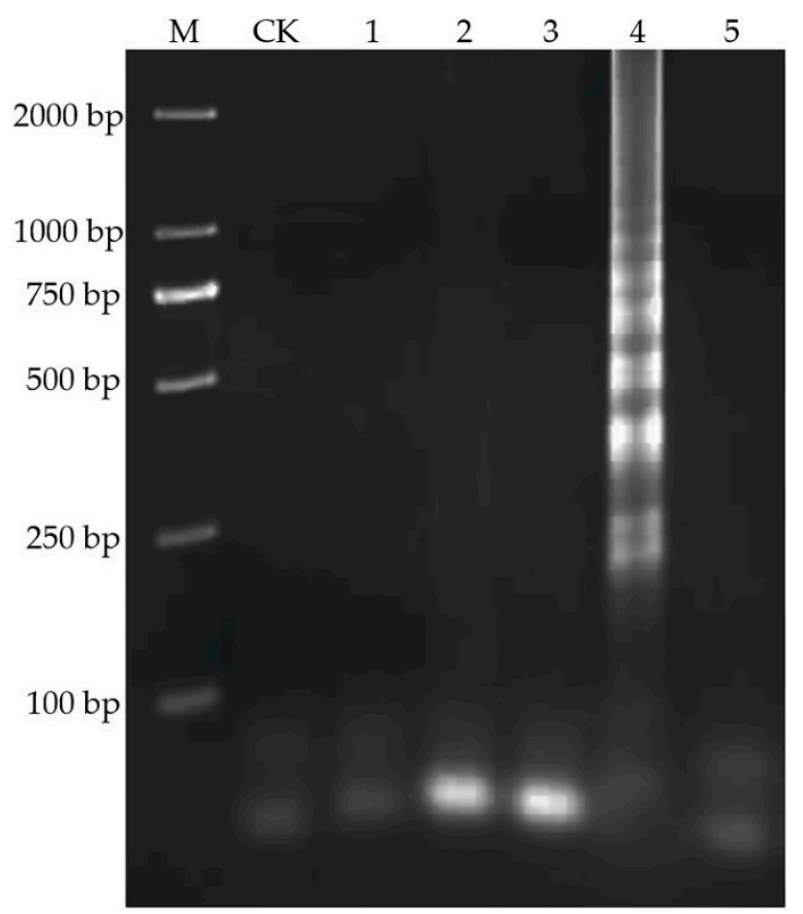

Figure 2. Analysis of LAMP products with five sets of designed primers by agarose gel electrophoresis. Lane M: DNA Marker; Lane CK: ddH2O; Line1-5: 1-5 sets of designed primers.

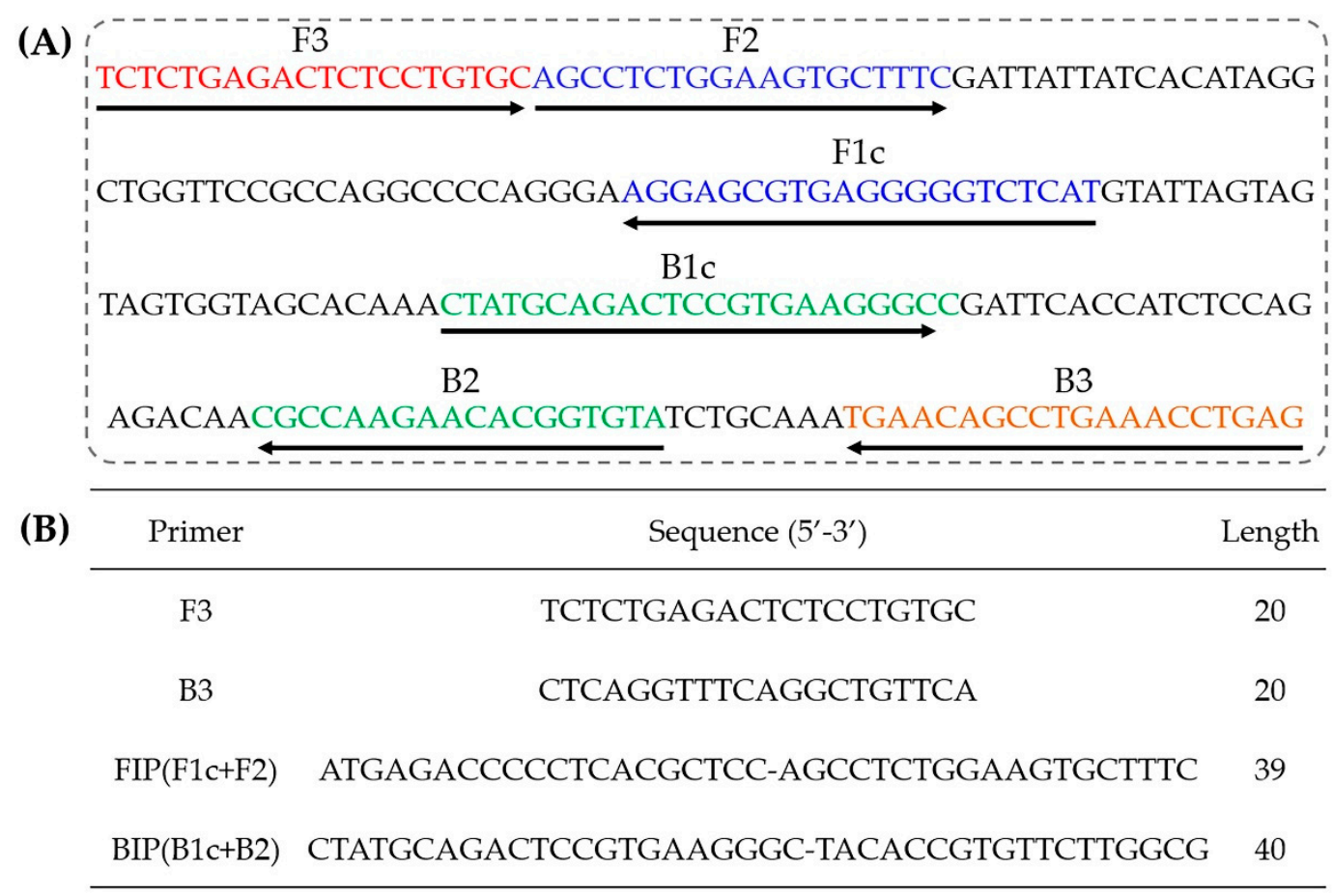

Figure 3. (A) Nucleotide sequence of phage V2-5 used to design LAMP primers. The locations and binding sequences of the primers are indicated by arrows and different colors. (B) Information of the fourth set of LAMP primers, a forward inner primer (FIP) consisting of F1c and F2, a backward inner primer (BIP) consisting of B1c and B2, a forward outer primer (F3) and a backward outer primer (B3). 


\subsection{Specificity of LAMP}

In order to evaluate the specificity of the LAMP reaction, the helper phage M13KO7, the anti-aflatoxin $\mathrm{scFv}$ phage $1 \mathrm{~A} 7$ [26] and the phage V2-5 were selected as templates for LAMP reaction, and $\mathrm{ddH}_{2} \mathrm{O}$ instead of the template was used as the negative control. Each amplification product was subjected to $2 \%$ agarose gel electrophoresis (Figure 4 ). The results showed that only the nanobody-phage V2-5 produced trapezoid bands, while the other three phages did not, indicating that the primers have good specificity and can be used for the specific LAMP reaction of nanobody phage V2-5.

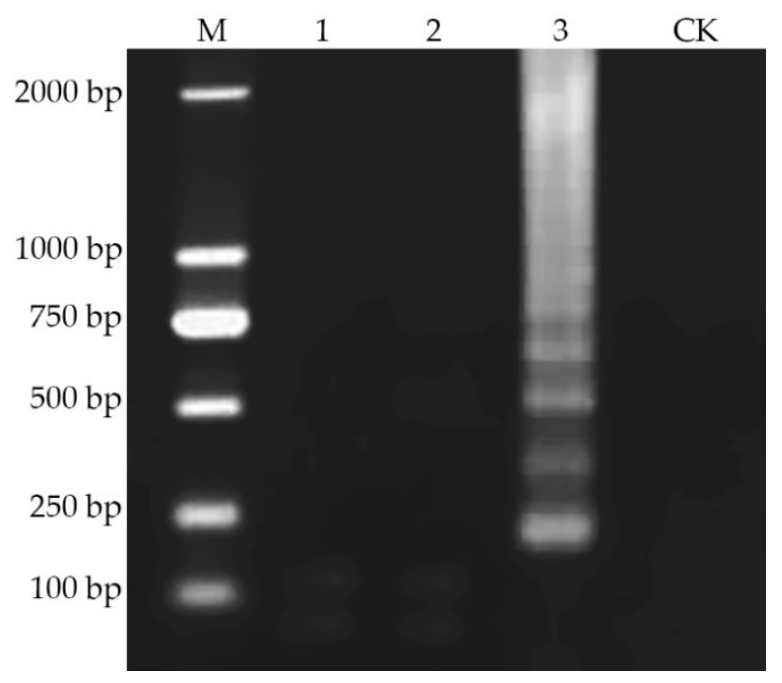

Figure 4. Specificity test of the LAMP Reaction. Specificity was tested by detecting helper phage M13KO7, anti-aflatoxin scFv phage 1A7 and phage V2-5; the results were observed by $2 \%$ agarose gel electrophoresis under imaging system. Line M: DNA Marker; Lane CK: ddH2O; Line 1: helper phage M13KO7; Line 2: scFv phage 1A7; Line 3: nanobody phage V2-5.

\subsection{Visual Inspection of LAMP}

By adding an indicator to the LAMP system, the detection results can be identified by the naked eye easily. The indicator used in this study was hydroxy-naphthol blue (HNB), a metal ion indicator. When HNB was first added to the reaction system, the color of the mixture was violet; during the reaction, $\mathrm{Mg}^{2+}$ combined with the pyrophosphate ion, a by-product of LAMP, to form magnesium pyrophosphate precipitation; meanwhile, the color of the mixture changed from violet to sky blue with the decrease of $\mathrm{Mg}^{2+}$ concentration. In order to investigate whether the visual results were consistent with those of DNA gel electrophoresis, phage V2-5 was diluted into concentration gradients of $10^{2}$, $10^{3}, 10^{4}, 10^{5}, 10^{6}$ and $10^{7} \mathrm{pfu} / \mathrm{mL}$, and detected by LAMP, respectively. The visual results are shown in Figure 5A, and the DNA gel electrophoresis results are shown in Figure 5B. The detection limits of phage V2-5 obtained by the two methods were both $10^{3} \mathrm{pfu} / \mathrm{mL}$. Therefore, the visual detection method can be used instead of DNA gel electrophoresis to simplify the detection process.

\subsection{Visual Detection Limit of iLAMP}

A series of concentrations $(2,1,0.4,0.2,0.1,0.04$ and $0.02 \mu \mathrm{g} / \mathrm{kg})$ of aflatoxin standards were prepared in $10 \%$ methanol/PBS (v/v) and detected by the iLAMP method. The color change of the tubes was observed with the naked eye. As shown in Figure 6, with the decrease of aflatoxin concentration, the color of the tubes gradually changed from violet to sky blue. The lowest concentration of aflatoxin under violet color was taken as the visual detection limit for iLAMP. Therefore, the visual detection limits of iLAMP for $\mathrm{AFB}_{1}, \mathrm{AFB}_{2}, \mathrm{AFG}_{1}$ and $\mathrm{AFG}_{2}$ were $0.1,0.1,0.2$ and $1 \mu \mathrm{g} / \mathrm{kg}$, respectively. 
(A)
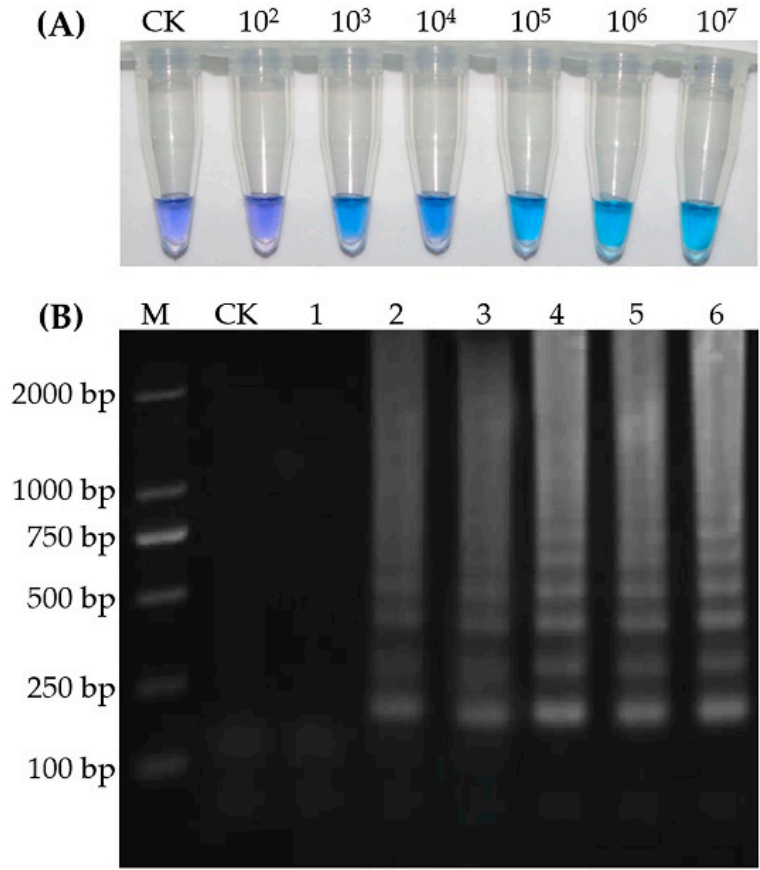

Figure 5. (A) Visual Inspection result of LAMP. The color change of the mixture in the tubes was observed by the naked eye. (B) Agarose gel electrophoresis result of the LAMP products. M represents DNA Marker; CK represents negative control; $1-6$ represents $10^{2}, 10^{3}, 10^{4}, 10^{5}, 10^{6}$ and $10^{7} \mathrm{pfu} / \mathrm{mL}$ phage V2-5, respectively.

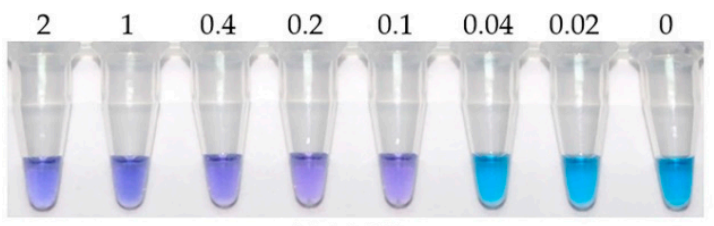

(A) $\mathrm{AFB}_{1}$

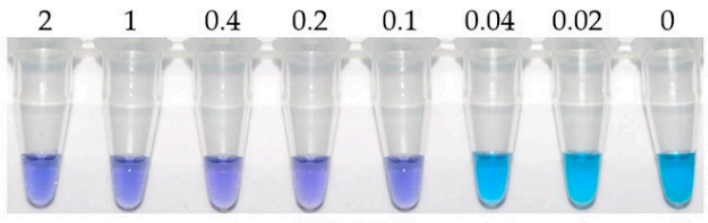

(B) $\mathrm{AFB}_{2}$

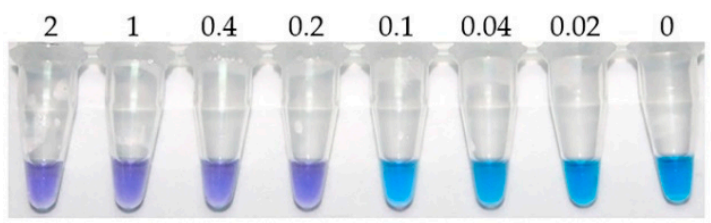

(C) $\mathrm{AFG}_{1}$

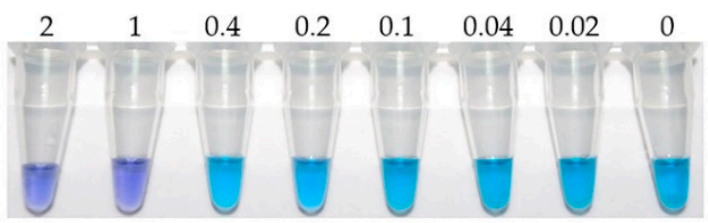

(D) $\mathrm{AFG}_{2}$

Figure 6. Visual detection limits of iLAMP for four aflatoxins. A series of concentrations $(2,1,0.4,0.2$, $0.1,0.04$ and $0.02 \mu \mathrm{g} / \mathrm{kg}$ ) of aflatoxin standards were prepared in $10 \%$ methanol/PBS (v/v) and detected by iLAMP method; a sample without aflatoxin was used as blank control $(0 \mu \mathrm{g} / \mathrm{kg})$. (A) Visual detection limit of $\mathrm{AFB}_{1}$, (B) Visual detection limit of $\mathrm{AFB}_{2},(\mathbf{C})$ Visual detection limit of $\mathrm{AFG}_{1}$, (D) Visual detection limit of $\mathrm{AFG}_{2}$.

\subsection{Solvent and Matrix Effects}

Due to their low solubility in water, aflatoxins are usually extracted from samples by high concentrations of methanol. In real sample detection, the binding of antibody and antigen is often interfered with by either methanol or sample matrix in the sample extract. Dilution is a common and simple way to eliminate these effects [12].

The extract of blank peanut sample was diluted with PBS by 2, 4, 8, 16, and 20 times. The phage V2-5 was mixed with an equal volume of each sample dilution and detected by the iLAMP method. The color of the tube under each dilution ratio was observed with the naked eye, and the results are shown in Figure 7. When the sample extract was diluted 2, 4 and 8 times, the color of the tubes were the 
same as the blank control (violet), indicating that the sample extract affected the binding of mAb $1 \mathrm{C} 11$ and phage V2-5. When the extract was diluted more than 16 times, the amplification began, indicating that the effect of the sample extract can be ignored. Since a higher dilution ratio would reduce the sensitivity of the method, 16 times was chosen as the best dilution ratio of the sample extract.

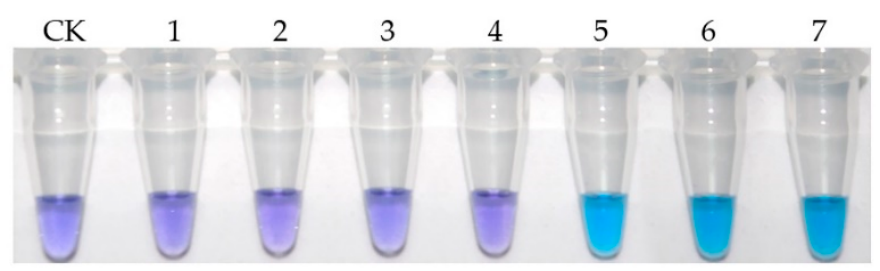

Figure 7. Effects of sample extract dilution ratio to the reaction between $\mathrm{mAb} 1 \mathrm{C} 11$ and phage V2-5. CK represented negative control without sample extract and phage V2-5; 1 represented undiluted sample extract; 2-6 respectively represented 2, 4, 8, 16, and 20 times dilution of the sample extract; 7 represented positive control with PBS and phage V2-5.

\subsection{Assay Validation with Peanut Samples}

To validate the assay, 20 naturally contaminated peanut samples were analyzed by iLAMP and high performance liquid chromatography (HPLC) methods, respectively. The results obtained by the two methods are shown in Table 1. The visual inspection results of iLAMP were consistent with those from HPLC. The five replications within the iLAMP assay also showed good repeatability, demonstrating that the newly developed iLAMP method can be applied to the determination of aflatoxin in real samples.

Table 1. Results of high performance liquid chromatography (HPLC) and iLAMP for aflatoxins in peanut samples.

\begin{tabular}{|c|c|c|c|c|c|}
\hline \multirow{2}{*}{ Sample } & \multicolumn{4}{|c|}{ HPLC $(\mu \mathrm{g} / \mathrm{kg})$} & \multirow{2}{*}{$\begin{array}{c}\text { iLAMP } \\
(n=5)\end{array}$} \\
\hline & $\mathbf{A F B}_{1}$ & $\mathbf{A F B}_{2}$ & $\mathrm{AFG}_{1}$ & $\mathrm{AFG}_{2}$ & \\
\hline 1 & 3.39 & 0.20 & $\mathrm{ND}^{\mathrm{a}}$ & ND & $\mathrm{V}^{\mathrm{b}}, \mathrm{V}, \mathrm{V}, \mathrm{V}, \mathrm{V}$ \\
\hline 2 & 3.73 & 0.36 & ND & ND & $\mathrm{V}, \mathrm{V}, \mathrm{V}, \mathrm{V}, \mathrm{V}$ \\
\hline 3 & 2.27 & 0.22 & ND & ND & $\mathrm{V}, \mathrm{V}, \mathrm{V}, \mathrm{V}, \mathrm{V}$ \\
\hline 4 & 23.60 & 3.60 & ND & ND & $\mathrm{V}, \mathrm{V}, \mathrm{V}, \mathrm{V}, \mathrm{V}$ \\
\hline 5 & 2.56 & 0.31 & ND & ND & $\mathrm{V}, \mathrm{V}, \mathrm{V}, \mathrm{V}, \mathrm{V}$ \\
\hline 6 & 12.41 & 2.30 & ND & ND & $\mathrm{V}, \mathrm{V}, \mathrm{V}, \mathrm{V}, \mathrm{V}$ \\
\hline 7 & 0.78 & ND & ND & ND & $\mathrm{S}^{\mathrm{c}}, \mathrm{S}, \mathrm{S}, \mathrm{S}, \mathrm{S}$ \\
\hline 8 & 4.90 & 0.61 & ND & ND & $\mathrm{V}, \mathrm{V}, \mathrm{V}, \mathrm{V}, \mathrm{V}$ \\
\hline 9 & 1.97 & ND & ND & ND & $\mathrm{V}, \mathrm{V}, \mathrm{V}, \mathrm{V}, \mathrm{V}$ \\
\hline 10 & 20.68 & 1.66 & ND & ND & $\mathrm{V}, \mathrm{V}, \mathrm{V}, \mathrm{V}, \mathrm{V}$ \\
\hline 11 & 1.02 & ND & ND & ND & $S, S, S, S, S$ \\
\hline 12 & 6.24 & 1.02 & ND & ND & $\mathrm{V}, \mathrm{V}, \mathrm{V}, \mathrm{V}, \mathrm{V}$ \\
\hline 13 & 16.43 & 1.92 & 2.36 & ND & $\mathrm{V}, \mathrm{V}, \mathrm{V}, \mathrm{V}, \mathrm{V}$ \\
\hline 14 & 0.94 & ND & ND & ND & S, S, S, S, S \\
\hline 15 & 16.84 & 3.32 & ND & ND & $\mathrm{V}, \mathrm{V}, \mathrm{V}, \mathrm{V}, \mathrm{V}$ \\
\hline 16 & 28.86 & 1.30 & ND & ND & $\mathrm{V}, \mathrm{V}, \mathrm{V}, \mathrm{V}, \mathrm{V}$ \\
\hline 17 & 2.24 & 0.44 & ND & ND & $\mathrm{V}, \mathrm{V}, \mathrm{V}, \mathrm{V}, \mathrm{V}$ \\
\hline 18 & 15.88 & 2.25 & ND & ND & $\mathrm{V}, \mathrm{V}, \mathrm{V}, \mathrm{V}, \mathrm{V}$ \\
\hline 19 & 5.18 & 0.66 & ND & ND & $\mathrm{V}, \mathrm{V}, \mathrm{V}, \mathrm{V}, \mathrm{V}$ \\
\hline 20 & 0.34 & ND & ND & ND & $S, S, S, S, S$ \\
\hline
\end{tabular}

${ }^{a}$ ND: not detectable. ${ }^{b}$ V: violet, positive result. ${ }^{c} \mathrm{~S}$ : sky blue, negative result. 


\subsection{Comparison of iLAMP with Previous Research}

Based on mAb 1C11, we have previously established a variety of immunoassays for aflatoxins, which can be divided into two categories: methods using aflatoxin conjugates (ELISA and ICA), and methods using nanobody instead of conjugates (nanobody-based ELISA and nanobody-phage-based real-time iPCR). The comparison of assay parameters and analytical characteristics between iLMAP and previous research is shown in Table 2. Obviously, the methods with aflatoxin conjugates were more sensitive (in $\mathrm{AFB}_{1}$ detection). However, it is more environmentally friendly, safer for operators, and cost effective to use nanobody instead of the conjugates. Compared with the other two methods using nanobodies, the iLAMP established in this work has the highest sensitivity, and also achieves rapid detection in the field.

Table 2. Comparison between iLAMP and previous research.

\begin{tabular}{ccccc}
\hline Method & Immune Reagents & Matrix & Sensitivity $(\mu \mathrm{g} / \mathbf{k g})$ & Reference \\
\hline ELISA & $1 \mathrm{C} 11+\mathrm{AFB}_{1}$-BSA & Standard solution & 0.0012 & {$[25]$} \\
ICA & $1 \mathrm{C} 11+\mathrm{AFB}_{1}$-OVA & Peanut & 0.03 & {$[27]$} \\
ELISA & $1 \mathrm{C} 11+$ Nanobody & Peanut, corn, rice & 13.8 & {$[12]$} \\
iPCR & $1 C 11+$ Nanobody-phage & Peanut, corn, rice, feedstuff & 5.6 & {$[13]$} \\
iLAMP & $1 \mathrm{C} 11+$ Nanobody-phage & Peanut & 1.6 & $-{ }^{\text {a }}$ \\
\hline
\end{tabular}

a: The data were obtained in this work.

\section{Discussion}

\subsection{Primer Design of LAMP}

LAMP primers should be designed in accordance with specific requirements in addition to general PCR primer design principles. For example, the target gene sequence for primer design should be less than $22 \mathrm{kbp}$. Furthermore, the annealing temperature of primers should be between $60-65{ }^{\circ} \mathrm{C}$, which was also the optimal temperature for Bst DNA polymerase. In this study, five sets of primers were designed by LAMP online primer design software, and a set of effective primers was obtained after screening. In addition, it has been reported that the LAMP reaction efficiency could be improved by adding two Loop Primers (Loop Primer F and Loop Primer B) to the LAMP system, and the reaction time could be shortened to half of the original [28]. Therefore, loop primers can be utilized in our following study to shorten the reaction time and further simplify the detection process.

\subsection{Visual Inspection Indicator of LAMP}

By adding an indicator to LAMP system, the detection results can be determined by the naked eye, which eliminates the tedious procedures of DNA gel electrophoresis. The most widely used indicator in LAMP is SYBR Green I, which is a highly sensitive DNA fluorescent dye. The LAMP reaction mixture will turn green after the addition of SYBR Green I if there is specific amplification; otherwise, the mixture will remain orange. However, the disadvantage of SYBR Green I is that it must be added to the tube after LAMP reaction. By opening the lid and adding the indicator, the probability of contamination will be greatly increased, which may lead to false positive or negative results. The indicator HNB used in this study can be directly added to the LAMP system before the reaction. Thus, there is no need to open the lid after the reaction, which simplified the operation process and kept the whole detection process within a closed environment; more importantly, the probability of contamination was reduced.

\subsection{Solvent and Matrix Affects}

In this study, aflatoxins were extracted by $80 \%$ methanol/water (v/v); as a result, the activity of mAb $1 \mathrm{C} 11$ was interfered with by methanol and sample matrix in the sample extract. Eventually, the solvent and matrix effects were eliminated by dilution of the sample extract. However, the sensitivity of iLAMP is lower than the immunochromatographic assay previously established in our laboratory [27]. 
The possible reason is that the dilution ratio of iLAMP (16 times) is higher than that of the immunochromatographic method (7.5 times). This is also consistent with the reports that a high dilution ratio will reduce the sensitivity of the method [29]. After dilution, the detection limits of iLAMP for aflatoxin $B_{1}, B_{2}, G_{1}$ and $G_{2}$ in real samples were $1.6,1.6,3.2$ and $16 \mu \mathrm{g} / \mathrm{kg}$, respectively.

\subsection{Application Prospect of iLAMP}

As an improved nucleic acid amplification method with advantages of high specificity, and fast and simple operation, LAMP is widely used in detection of bacteria [30], viruses [31] and genes [32], while its application in small molecule detection is rarely reported. In this study, LAMP was applied to the detection of aflatoxin for the first time by using anti-idiotypic nanobody phage V2-5. Compared with immunochromatography assay which also adopts the visual detection method, this method does not need complex procedures such as antibody labeling and test strip assembling. In addition, the iLAMP can be applied for $\mathrm{AFB}_{1}$ detection according to the maximum residue limits (MRL) for peanuts in most countries (e.g., $20 \mu \mathrm{g} / \mathrm{kg}$ in China and USA, $10 \mu \mathrm{g} / \mathrm{kg}$ in Japan). According to the MRL of total Aflatoxins $(15 \mu \mathrm{g} / \mathrm{kg})$ set for peanut by Codex, the iLAMP is also applicable since the proportion of four aflatoxins $\left(B_{1}, B_{2}, G_{1}\right.$ and $\left.G_{2}\right)$ is generally 1:0.1:0.3:0.03 when they occur simultaneously [3]. In conclusion, the iLAMP method established in this study is fast and simple, does not rely on expensive equipment, and has low operational requirements for operators. This study provides a new method for aflatoxin immunoassay, which can be applied to on-site rapid screening of real samples, and is expected to be popularized and applied in situations lacking instruments and equipment.

\section{Materials and Methods}

\subsection{Materials}

Anti-aflatoxin mAb 1C11 and anti-idiotypic nanobody phage V2-5 specific for mAb $1 \mathrm{C} 11$ were produced in our laboratory as previously described. Aflatoxin $B_{1}, B_{2}, G_{1}$, and $G_{2}$ standard solutions, polyethylene glycol 8000 (PEG8000), Tween-20, betaine, bovine serum albumin (BSA), and hydroxy naphthol blue (HNB) were purchased from Sigma-Aldrich (Merck KGaA, Darmstadt, Germany). The helper phage M13KO7, E. coli ER2738, and Bst DNA polymerase were purchased from New England Biolabs (Ipswich, MA, USA). dNTPs were purchased from Takara (Kyoto, Japan). The water was produced by a Milli-Q purification system (Merck KGaA, Darmstadt, Germany). The iLAMP method was validated with an Agilent 1100 HPLC system (Santa Clara, CA, USA).

\subsection{Phage Preparation}

The recombinant E. coli ER2738 containing nanobody V2-5 phagemid were inoculated into $1 \mathrm{~mL}$ ampicillin-SB $(100 \mu \mathrm{g} / \mathrm{mL})$ medium, with shaking $(225 \mathrm{rpm})$ at $37^{\circ} \mathrm{C}$ overnight. The $1 \mathrm{~mL}$ overnight culture of $E$. coli was added to $100 \mathrm{~mL}$ ampicillin-SB $(100 \mu \mathrm{g} / \mathrm{mL})$ medium, followed by shaking $(250 \mathrm{rpm})$ at $37^{\circ} \mathrm{C}$ until $\mathrm{OD}_{600}$ reached 0.5-0.6. After being infected with helper phages M13K07 $\left(10^{11}-10^{12} \mathrm{pfu} / \mathrm{mL}\right)$ by incubation at $37^{\circ} \mathrm{C}$ for $30 \mathrm{~min}$, kanamycin was added into the culture at a $70 \mu \mathrm{g} / \mathrm{mL}$ final concentration, followed by shaking $(225 \mathrm{rpm})$ overnight at $37^{\circ} \mathrm{C}$. The overnight culture was centrifuged $(10,000 \mathrm{rpm})$ for $15 \mathrm{~min}$ at $4{ }^{\circ} \mathrm{C}$, and the supernatant was mixed with $20 \% \mathrm{PEG} / \mathrm{NaCl}$ by incubation on ice for $2 \mathrm{~h}$. The mixture was centrifuged $(10,000 \mathrm{rpm})$ for $30 \mathrm{~min}$ and the precipitate (phage particles) was resuspended with $2 \mathrm{~mL}$ of BSA/PBS (PBS containing 0.5\% BSA), followed by centrifuging at $12,000 \mathrm{rpm}$ for $5 \mathrm{~min}$. The supernatant was filtered with a $0.22 \mu \mathrm{M}$ filter and mixed with an equal volume of sterilized glycerin. The phages were stored at $-20{ }^{\circ} \mathrm{C}$ after titer measurement.

\subsection{Primer Design}

The specific LAMP primers based on the DNA sequence of the anti-idiotypic nanobody-phage V2-5 were designed by an online primer designing tool named Primer Explorer V4 (http://primerexplorer.jp/ elamp4.0.0/index.html) developed by Eiken Chemical Co., Ltd. (Tochigi, Japan). 


\subsection{LAMP Reaction}

The LAMP mixture contained $1.6 \mu \mathrm{M}$ each of FIP and BIP, $0.2 \mu \mathrm{M}$ each of F3 and B3, $1.4 \mathrm{mM}$ dNTPs, $0.8 \mathrm{M}$ betaine, $8 \mathrm{mM} \mathrm{MgSO} 4,20 \mathrm{mM}$ Tris- $\mathrm{HCl}(\mathrm{pH} 8.8), 10 \mathrm{mM} \mathrm{KCl}, 10 \mathrm{mM}\left(\mathrm{NH}_{4}\right)_{2} \mathrm{SO}_{4}, 0.1 \%$ Tween-20, $8 \mathrm{U}$ of Bst DNA polymerase, $150 \mu \mathrm{M} \mathrm{HNB}, 1 \mu \mathrm{L}$ of target DNA and $\mathrm{ddH}_{2} \mathrm{O}$ in a final volume of $25 \mu \mathrm{L}$. The reaction was performed in $0.2 \mathrm{~mL}$ PCR tubes which placed in a water bath at $63^{\circ} \mathrm{C}$ for $40 \mathrm{~min}$, and then $95^{\circ} \mathrm{C}$ for $2 \mathrm{~min}$ to terminate the amplification. The tube contained all the LAMP reagents except the DNA template was set as the negative control. The results of LAMP were identified either by naked eye or DNA gel electrophoresis.

\section{5. iLAMP Method}

The PCR tubes were treated using a reported method [33]. $20 \mu \mathrm{L}$ of $0.8 \%$ glutaraldehyde in Milli-Q water was added to $0.2 \mathrm{~mL}$ PCR tubes followed by $5 \mathrm{~h}$ incubation at $37^{\circ} \mathrm{C}$. After six times washing with Milli-Q water, the tubes were coated with $20 \mu \mathrm{L}$ of $\mathrm{mAb} 1 \mathrm{C} 11(10 \mu \mathrm{g} / \mathrm{mL})$ in carbonate buffer $(0.05 \mathrm{M}, \mathrm{pH} 9.6)$ at $4{ }^{\circ} \mathrm{C}$ overnight. Then, the tubes were blocked with $3 \%(\mathrm{w} / \mathrm{v})$ skimmed milk-PBS by incubation for $1.5 \mathrm{~h}$ at $37^{\circ} \mathrm{C}$. A series concertation of aflatoxin standards prepared in $10 \%(\mathrm{v} / \mathrm{v})$ methanol/PBS was mixed with an equal volume of phage V2-5 $\left(10^{7} \mathrm{pfu} / \mathrm{mL}\right) .20 \mu \mathrm{L}$ of each mixture was added into the PCR tube and incubated at $37^{\circ} \mathrm{C}$ for $1 \mathrm{~h}$. The tubes were washed six times with PBST (PBS with $0.05 \%$ Tween-20) followed by six washings with Milli-Q water in order to remove the unbound phages. The phages captured by mAb 1C11 were used as DNA template and detected by LAMP.

\subsection{Sample Analysis}

The peanut samples obtained from local markets were ground by a grinder and stored at $-20{ }^{\circ} \mathrm{C}$ before use. $5 \mathrm{~g}$ of each sample was extracted by $25 \mathrm{~mL}$ of $80 \%$ methanol/water $(\mathrm{v} / \mathrm{v})$ and incubated at room temperature with shaking ( $250 \mathrm{rpm}$ ) for $15 \mathrm{~min}$. Subsequently, the mixture was centrifuged at $5000 \mathrm{rpm}$ for $5 \mathrm{~min}$ at room temperature, and the supernatant was further used for sample analysis. The solvent and matrix effects were tested by blank samples. A comparative study was carried out by both iLAMP and HPLC for the validation of the iLAMP method. The aflatoxin purification procedure of HPLC used an immunoaffinity column (IAC) which was made by our laboratory as previously described [34]. The HPLC system was equipped with a $150 \times 4.6 \mathrm{~mm} \mathrm{C}_{18}$ column and a fluorescence detector. The excitation and emission wavelengths were respectively set as 360 and $440 \mathrm{~nm}$. In the mobile phase, acetonitrile and water performed at a flow rate of $1.0 \mathrm{~mL} / \mathrm{min}$. The injection volume was fixed as $20 \mu \mathrm{L}$.

Author Contributions: Conceptualization, Q.Z. and J.L.; methodology, Q.Z. and X.T.; software, X.H.; validation, J.L. and X.H.; investigation, X.H.; resources, X.T.; data curation, H.W.; writing-original draft preparation, J.L.; writing-review and editing, X.H. and X.T.; visualization, H.W.; project administration, J.L.; funding acquisition, J.L. and H.W. All authors have read and agreed to the published version of the manuscript.

Funding: This research was funded by Natural Science Foundation of Hubei Province (2018CFB135), and Fundamental Research Funds for the Central Universities, South-Central University for Nationalities (CZQ17003).

Conflicts of Interest: The authors declare no conflict of interest.

\section{References}

1. Yabe, K.; Ando, Y.; Hamasaki, T. Biosynthetic relationship among aflatoxins B1, B2, G1, and G2. Appl. Environ. Microbiol. 1988, 54, 2101-2106. [CrossRef]

2. Some Traditional Herbal Medicines, Some Mycotoxins, Naphthalene and Styrene; World Health Organization: Geneva, Switzerland, 2002.

3. Kensler, T.W.; Roebuck, B.D.; Wogan, G.N.; Groopman, J.D. Aflatoxin: A 50-year odyssey of mechanistic and translational toxicology. Toxicol. Sci. 2011, 120, S28-S48. [CrossRef] 
4. Ismail, A.; Goncalves, B.L.; de Neeff, D.V.; Ponzilacqua, B.; Coppa, C.; Hintzsche, H.; Sajid, M.; Cruz, A.G.; Corassin, C.H.; Oliveira, C.A.F. Aflatoxin in foodstuffs: Occurrence and recent advances in decontamination. Food Res. Int. 2018, 113, 74-85. [CrossRef]

5. Yakubu, A.; Vyas, A. Aflatoxin: Occurrence, Regulation, and Detection in Food and Feed. In Microbial Biotechnology: Basic Research and Applications; Singh, J., Vyas, A., Wang, S., Prasad, R., Eds.; Springer: Singapore, 2020; pp. 337-353. [CrossRef]

6. Shephard, G.S. Aflatoxin analysis at the beginning of the twenty-first century. Anal. Bioanal. Chem. 2009, 395, 1215-1224. [CrossRef]

7. Li, P.; Zhang, Q.; Zhang, W.; Zhang, J.; Chen, X.; Jiang, J.; Xie, L.; Zhang, D. Development of a class-specific monoclonal antibody-based ELISA for aflatoxins in peanut. Food Chem. 2009, 115, 313-317. [CrossRef]

8. Zhang, D.; Li, P.; Yang, Y.; Zhang, Q.; Zhang, W.; Xiao, Z.; Ding, X. A high selective immunochromatographic assay for rapid detection of aflatoxin B 1. Talanta 2011, 85, 736-742. [CrossRef]

9. Ma, H.; Sun, J.; Zhang, Y.; Bian, C.; Xia, S.; Zhen, T. Label-free immunosensor based on one-step electrodeposition of chitosan-gold nanoparticles biocompatible film on Au microelectrode for determination of aflatoxin B1 in maize. Biosens. Bioelectron. 2016, 80, 222-229. [CrossRef]

10. Berg, E.A.; Fishman, J.B. Labeling Antibodies. Cold Spring Harb. Protoc. 2020, 2020, 099242. [CrossRef]

11. Li, P.; Zhang, Q.; Zhang, W. Immunoassays for aflatoxins. TrAC Trends Anal. Chem. 2009, 28, 1115-1126. [CrossRef]

12. Wang, Y.; Li, P.; Majkova, Z.; Bever, C.R.; Kim, H.J.; Zhang, Q.; Dechant, J.E.; Gee, S.J.; Hammock, B.D. Isolation of Alpaca Anti-Idiotypic Heavy-Chain Single-Domain Antibody for the Aflatoxin Immunoassay. Anal. Chem. 2013, 85, 8298-8303. [CrossRef]

13. Lei, J.; Li, P.; Zhang, Q.; Wang, Y.; Zhang, Z.; Ding, X.; Zang, W. Anti-Idiotypic Nanobody-Phage Based Real-Time Immuno-PCR for Detection of Hepatocarcinogen Aflatoxin in Grains and Feedstuffs. Anal. Chem. 2014, 86, 10841-10846. [CrossRef]

14. Notomi, T.; Okayama, H.; Masubuchi, H.; Yonekawa, T.; Watanabe, K.; Amino, N.; Hase, T. Loop-mediated isothermal amplification of DNA. Nucleic Acids Res. 2000, 28, e63. [CrossRef]

15. Sagcan, H.; Kara, N.T. Detection of Potato ring rot Pathogen Clavibacter michiganensis subsp. s epedonicus by Loop-mediated isothermal amplification (LAMP) assay. Sci. Rep. 2019, 9, 1-8. [CrossRef]

16. Rivero, R.; Bisio, M.; Velázquez, E.B.; Esteva, M.I.; Scollo, K.; González, N.L.; Altcheh, J.; Ruiz, A.M. Rapid detection of Trypanosoma cruzi by colorimetric loop-mediated isothermal amplification (LAMP): A potential novel tool for the detection of congenital Chagas infection. Diagn. Microbiol. Infect. Dis. 2017, 89, $26-28$. [CrossRef]

17. Li, R.; Shi, J.; Liu, B.; Zhang, D.; Zhao, X.; Yang, L. International collaborative ring trial of four gene-specific loop-mediated isothermal amplification assays in GMO analysis. Food Control 2018, 84, 278-283. [CrossRef]

18. Niessen, L.; Bechtner, J.; Fodil, S.; Taniwaki, M.H.; Vogel, R.F. LAMP-based group specific detection of aflatoxin producers within Aspergillus section Flavi in food raw materials, spices, and dried fruit using neutral red for visible-light signal detection. Int. J. Food Microbiol. 2018, 266, 241-250. [CrossRef]

19. Kundapur, R.R.; Nema, V. Loop-mediated isothermal amplification: Beyond microbial identification. Cogent Biol. 2016, 2, 1137110. [CrossRef]

20. Nurul Najian, A.B.; Foo, P.C.; Ismail, N.; Kim-Fatt, L.; Yean, C.Y. Probe-specific loop-mediated isothermal amplification magnetogenosensor assay for rapid and specific detection of pathogenic Leptospira. Mol. Cell. Probes 2019, 44, 63-68. [CrossRef]

21. Zhu, L.; Xu, Y.; Cheng, N.; Xie, P.; Shao, X.; Huang, K.; Luo, Y.; Xu, W. A facile cascade signal amplification strategy using DNAzyme loop-mediated isothermal amplification for the ultrasensitive colorimetric detection of Salmonella. Sens. Actuators B Chem. 2017, 242, 880-888. [CrossRef]

22. Reid, M.S.; Le, X.C.; Zhang, H. Exponential Isothermal Amplification of Nucleic Acids and Assays for Proteins, Cells, Small Molecules, and Enzyme Activities: An EXPAR Example. Angew. Chem. Int. Ed. 2018, 57, 11856-11866. [CrossRef]

23. Pourhassan-Moghaddam, M.; Rahmati-Yamchi, M.; Akbarzadeh, A.; Daraee, H.; Nejati-Koshki, K.; Hanifehpour, Y.; Joo, S. Protein detection through different platforms of immuno-loop-mediated isothermal amplification. Nanoscale Res. Lett. 2013, 8, 1-11. [CrossRef] 
24. Iwamoto, T.; Sonobe, T.; Hayashi, K. Loop-Mediated Isothermal Amplification for Direct Detection of Mycobacterium tuberculosis Complex, M. avium, and M. intracellulare in Sputum Samples. J. Clin. Microbiol. 2003, 41, 2616-2622. [CrossRef]

25. Zhang, D.H.; Li, P.W.; Zhang, Q.; Zhang, W.; Huang, Y.L.; Ding, X.X.; Jiang, J. Production of ultrasensitive generic monoclonal antibodies against major aflatoxins using a modified two-step screening procedure. Anal. Chim. Acta. 2009, 636, 63-69. [CrossRef]

26. Li, X.; Li, P.; Lei, J.; Zhang, Q.; Zhang, W.; Li, C. A simple strategy to obtain ultra-sensitive single-chain fragment variable antibodies for aflatoxin detection. RSC Adv. 2013, 3, 22367-22372. [CrossRef]

27. Zhang, D.H.; Li, P.W.; Zhang, Q.; Zhang, W. Ultrasensitive nanogold probe-based immunochromatographic assay for simultaneous detection of total aflatoxins in peanuts. Biosens. Bioelectron. 2011, 26, 2877-2882. [CrossRef]

28. Nagamine, K.; Hase, T.; Notomi, T. Accelerated reaction by loop-mediated isothermal amplification using loop primers. Mol. Cell. Probes 2002, 16, 223-229. [CrossRef]

29. Apollonio, L.G.; Whittall, I.R.; Pianca, D.J.; Kyd, J.M.; Maher, W.A. Matrix effect and cross-reactivity of select amphetamine-type substances, designer analogues, and putrefactive amines using the Bio-Quant direct ELISA presumptive assays for amphetamine and methamphetamine. J. Anal. Toxicol. 2007, 31, 208-213. [CrossRef]

30. Vergara, A.; Boutal, H.; Ceccato, A.; López, M.; Cruells, A.; Bueno-Freire, L.; Moreno-Morales, J.; Puig de la Bellacasa, J.; Castro, P.; Torres, A. Assessment of a loop-mediated isothermal amplification (LAMP) assay for the rapid detection of pathogenic bacteria from respiratory samples in patients with hospital-acquired pneumonia. Microorganisms 2020, 8, 103. [CrossRef]

31. Kim, J.-G.; Baek, S.H.; Kim, S.; Kim, H.I.; Lee, S.W.; Kailasa, S.K.; Park, T.J. Rapid discriminative detection of dengue viruses via loop mediated isothermal amplification. Talanta 2018, 190, 391-396. [CrossRef]

32. Kanitkar, Y.H.; Stedtfeld, R.D.; Steffan, R.J.; Hashsham, S.A.; Cupples, A.M. Loop-mediated isothermal amplification (LAMP) for rapid detection and quantification of Dehalococcoides biomarker genes in commercial reductive dechlorinating cultures KB-1 and SDC-9. Appl. Environ. Microbiol. 2016, 82, 1799-1806. [CrossRef]

33. Liu, X.; Xu, Y.; Xiong, Y.H.; Tu, Z.; Li, Y.P.; He, Z.Y.; Qiu, Y.L.; Fu, J.H.; Gee, S.J.; Hammock, B.D. VHH phage-based competitive real-time immuno-polymerase chain reaction for ultrasensitive detection of ochratoxin A in cereal. Anal. Chem. 2014, 86,7471-7477. [CrossRef]

34. Ma, F.; Chen, R.; Li, P.; Zhang, Q.; Zhang, W.; Hu, X. Preparation of an immunoaffinity column with amino-silica gel microparticles and its application in sample cleanup for aflatoxin detection in agri-products. Molecules 2013, 18, 2222-2235. [CrossRef]

(C) 2020 by the authors. Licensee MDPI, Basel, Switzerland. This article is an open access article distributed under the terms and conditions of the Creative Commons Attribution (CC BY) license (http://creativecommons.org/licenses/by/4.0/). 